\title{
Feasibility and Impact of Placing Water Coolers on Sales of Sugar-Sweetened Beverages in Dutch Secondary School Canteens
}

\author{
Tommy L.S. Visscher ${ }^{a, b, c, d}$ Wendy CW van Hal ${ }^{\mathrm{e}} \quad$ Lobke Blokdijk $^{\mathrm{e}}$ Jaap C Seidell Jab,c,d $^{\mathrm{a}}$ \\ Carry M. Renders ${ }^{a, c}$ Wanda JE Bemelmans ${ }^{e}$ \\ ${ }^{a}$ Research Centre for the Prevention of Overweight Zwolle, Windesheim University of Applied Sciences, Zwolle, \\ ${ }^{\mathrm{b}}$ Institute for Health Sciences, VU University, \\ ${ }^{\mathrm{c}}$ EMGO Institute, VU Medical Centre, Amsterdam, the Netherlands \\ ${ }^{d}$ Public Health and Prevention Taskforce, European Association for the Study of Obesity, London, UK \\ ${ }^{e}$ Centre for Prevention and Health Services Research, National Institute for Public Health and the Environment, \\ Bilthoven, the Netherlands
}

\section{Key Words:}

Adolescent · Environment · Health promotion . Nutrition · Obesity · Prevention

\section{Summary}

Aims: The aim of this pilot study was to investigate the feasibility and effectiveness of placing water coolers on sugar-sweetened beverage sales at secondary schools (age 12-18 years) in the city of Zwolle, the Netherlands. Methods: Six schools, hosting 5,866 pupils, were divided in three intervention and three control schools. In the intervention schools, water coolers were placed in the canteen. Hidden observations were performed in one school to study the intervention's feasibility, and school personnel was interviewed. Beverage sales were monitored before and during the intervention. After the intervention period, 366 class 1 and 2 pupils completed a questionnaire about their drinking habits (response rate $81 \%$ ). Results: Placement of water coolers appeared to be a feasible intervention at secondary schools. However, it did not affect sales of sugar-sweetened beverages at schools. Although mean intake of sugar-sweetened beverages at school was high, more than $500 \mathrm{ml} /$ day for boys, and more than $250 \mathrm{ml} /$ day for girls, only a minority of these quantities was purchased at school. Conclusion: We conclude that placing water coolers as a single-issue intervention in secondary school canteens should not be prioritized in the combat against obesity.

\section{Introduction}

Childhood overweight prevalence is increasing worldwide [1], also in the Netherlands [2,3], and is associated with health consequences including hypertension, diabetes type 2 and joint problems, affecting quality of life [4]. The need for health promotion is now clear. School settings are important for health behaviour interventions, since schools provide the opportunity to target many children, and children spend a lot of time in the school environment $[5,6]$.

School-based interventions to counteract childhood overweight have been reported, and some have been shown to be effective [7-9]. Most of the described successful interventions aiming at weight management in children deal with multiple determinants and multiple stakeholders [7-9], likely explaining the success of those interventions. Although it is generally accepted that the causes of obesity are numerous and extremely complex [10-14], a promising one-issue intervention may be the placement of water coolers in order to reduce purchase of sugar-sweetened beverages from vending machines in schools $[15,16]$.

We had various reasons to design a large intervention study on placing water coolers in school canteens in order to reduce soft drink sales in school canteens: Besides increases in childhood obesity rates [1-3], soft drink consumption amongst teenagers is also increasing $[17,18]$. Sugar-sweetened beverages include non-alcoholic beverages such as sugar-sweetened soft drinks, ice teas and fruit juices [19]. In Dutch adolescents (13-18 years old) the consumption of sugar-sweetened bever-

Dr. Tommy L.S. Visscher

Research Centre for the Prevention of Overweight Zwolle (OPOZ)

Windesheim University of Applied Sciences, PO Box 10090

8000 GB Zwolle, the Netherlands

Tel. + 31384699096

Tommy.Visscher@falw.vu.n 
ages relatively increased between 1987 and 1998, with 50\% for boys and $33 \%$ for girls [20]. Several studies showed positive associations of sugar-sweetened beverage consumption with energy intake among adolescents, BMI and increased risk of becoming obese [21-23], which has been also confirmed by a review on cohort studies [16]. Availability of calorie-rich drinks available from vending machines and canteens at school has increased during the last few years while an alternative healthy choice is not always available [17, 24-27]. The potential public health impact of reducing energy intake is described to be large [28], and, finally, we are aware of only one earlier pilot study in which water provision was perceived as being expensive by the pupils [29]. Larger intervention studies on reducing beverage sales by placing water coolers have not been presented yet.

The first steps taken in our systematic approach in designing a larger intervention study were aimed at studying the feasibility of placing free water coolers in a pilot study and getting a first hint on the potential impact of placing free water coolers on beverage sales in Dutch school canteens. We decided to stop further designing our intervention study, because of the early conclusions we had drawn from our first steps in our systematic approach. The aim of the current paper is to share our findings and considerations in order to prevent the start of similar intervention studies in our region and to show the need for prioritizing other intervention studies in the combat against obesity.

\section{Material and Methods}

The present study took place as part of the evaluation of the Covenant on Overweight and Obesity, initiated by the Dutch Ministry of Health, Welfare and Sport. The Covenant on Overweight and Obesity was signed in 2005 by stakeholders in the field for a concerted strategy to produce a joint action plan focused on restoring the balance between energy intake and energy expenditure. Among the aims of the Covenant on Overweight and Obesity is to identify effective methods changing the school environment into a healthy environment for children [30]. The current study was a pilot study as a preparation for a larger study by the Ministry of Health, Welfare and Sport. The study aimed at the feasibility and impact of placing water coolers in secondary school canteens on sugar-sweetened beverage sales in those schools.

For our larger intervention study, we aimed at reaching secondary schools throughout the Netherlands. As part of the systematic approach we started inviting few schools only, in our city of Zwolle, a town in the northern part of the Netherlands with 114,635 inhabitants, until we found six participating schools, with at least a few including a relatively lower form of education. Eligible schools had to meet the following inclusion criteria: i) preparatory secondary vocational level had to be offered, ii) sugar-sweetened beverages had to be offered in school canteens, iii) at least 100 pupils had to be exposed to the school canteen. Nine secondary schools (out of 15 school locations) met these inclusion criteria and received a letter of invitation with information about the intervention. They were contacted by phone subsequently. Two schools were not interested in participating, since they already were involved in another project aiming at improving healthy behaviour, and one school was not interested because of the expected extra work load. The remaining six school locations were willing to participate. However, two of them could only be in- cluded as control schools, due to technical reasons and worries about spilling of water. Intervention schools were matched to these two control schools by educational level. Of the two remaining schools the school with the most pupils was selected as a control school. Average age was 14 years, with age ranging between 12 and 19 years. In the Netherlands, the lowest form of education has four grades, whereas the highest form has six grades. Questionnaire data were available from grade 1 and 2 only (age 12-14 years).

The intervention consisted of placing water coolers in school canteens, providing free water to pupils, without any communication such as lessons or media messages. It was on purpose that information was not provided since the aim was to study the effect of changing one single environmental factor in secondary schools on sugar-sweetened beverage sales. At the three intervention schools, the water coolers were placed next to every vending machine. The coolers were installed one week before the intervention period, but left inoperable until the first day of intervention. At the first day of the intervention period, free water bottles were handed out, that pupils could use to refill at the water cooler. A local water distribution company provided the water coolers and water bottles. In the three control schools no water coolers were placed, and no bottles were provided. The water coolers were operational during 3 months, e.g. from November 13, 2006 to February 22, 2007. October and the first 2 weeks of November 2006 were considered as the pre-intervention period (6 weeks). The outdoor temperature during the intervention period was on average $12{ }^{\circ} \mathrm{C}$ at the beginning and $7{ }^{\circ} \mathrm{C}$ at the end of the intervention (data not shown).

\section{Feasibility}

To study the feasibility of the water intervention and to obtain more insight in determining factors of pupils' habits according to usage of water coolers and vending machines, observations were performed in one intervention school by two researchers from 8:30 AM until 4:00 PM. Intervention school I was selected for the observations because this school had 'hidden' observation positions from a balcony. The observations were performed on two days (Tuesday and Thursday) during the pre-intervention period, the first week of the intervention period, and, after that, on one day (Thursday) every 3 or 4 weeks. The observations were registered on a structured form and captured frequency of usage of the vending machines and water coolers during the day (recorded for separate time intervals), characteristics of users (e.g. gender) and general behaviour of the pupils around the machines (e.g. if the freely provided water bottles were indeed used, queuing and other unforeseen events). Canteen personnel was asked to record potential problems with the use of the water coolers. Interviews with canteen personnel were performed by the same research assistant as who performed the observations in canteens. Topics of the interview addressed the feasibility of the intervention: Did personnel experience any spoiling of water, was there a need to shut the water supply because of inappropriate use of the water coolers?

In the intervention schools, the water consumption from the water coolers was read out from the water flow metres attached to the water coolers in decilitres $\left(0.1 \mathrm{dm}^{3}\right)$ on the first day and every Friday during the intervention period. The amount of water tapped was calculated to the unit 'ml/pupil/day'.

\section{Effects on Beverage Sales}

Beverage sales figures were monitored before and during the intervention. Beverages were categorized according to 'The Beverage Guidance Panel', ranking beverages from the lowest to the highest value based on caloric and nutrient contents and related health benefits and risks [19]. Six levels of beverages were defined, e.g. water (level 1), tea and coffee (level 2), low-fat, skimmed milk and soy beverages (level 3), non-calorically sweetened beverages (level 4), caloric beverages with some nutrients (level 5) and sugar-sweetened beverages (level 6). The present study focused on sugar-sweetened beverages as the main outcome parameter. Coffee, tea and milk sales were not measured. 
Table 1. Characteristics of intervention and control schools at baseline

\begin{tabular}{|c|c|c|c|c|c|c|}
\hline & \multicolumn{3}{|c|}{ Intervention schools } & \multicolumn{3}{|c|}{ Control schools } \\
\hline & I & II & III & IV & V & VI \\
\hline Number of pupils & 656 & 534 & 454 & 2,322 & 1,343 & 600 \\
\hline Education level $^{\mathrm{a}}$ & middle/high & all & low & all & all & low \\
\hline Number of vending machines & 2 & 2 & 1 & 2 & 3 & 2 \\
\hline Content of vending machines $(\text { level })^{\mathrm{b}}$ & $1,4,5,6$ & $1, .4,5,6$ & $1,4,5,6$ & $1,4,5,6$ & $1,4,5,6$ & 4,6 \\
\hline Additional sales of beverages, apart from vending machine & no & no & yes & no & no & yes \\
\hline
\end{tabular}

${ }^{a}$ Preparatory secondary vocational education: middle = senior general education; high = university preparatory education.

'Categorized according to 'The Beverage Guidance Panel' [12]: level 1 = water; level 4 = non-caloric beverages; level 5 = caloric beverages with some nutrients (sport drinks, fruit juices (part of level 5)); level 6 = sugar-sweetened beverages.

Table 2. Beverage sales before the intervention period in intervention and control school canteens (ml/pupil/day)

\begin{tabular}{lcc}
\hline & Intervention schools I, II, III & Control schools IV, V, VI \\
\hline Water & 2.1 & 1.0 \\
Non-caloric beverages & 2.6 & 4.7 \\
Caloric beverages with some & 4.9 & 1.8 \\
$\quad$ nutrients & 3.6 & \\
Sport drinks & 1.3 & 1.8 \\
Fruit juices & 17.9 & 0 \\
Sugar-sweetened beverages & & 25.4 \\
\hline
\end{tabular}

Beverage sales were measured in five separate periods: the pre-intervention period and four 3- or 4-week periods during the intervention, with two periods before and two periods after the Christmas holidays. Every last day of a period, the sales from vending machines and canteens were recorded. For control school V, data of the last intervention period are not available.

\section{Post-Intervention Questionnaire Data}

During this pilot study, we experienced that only a minority of beverages consumed at school seemed to be sold at school. Therefore, we delivered a questionnaire in May 2007, 3 months after the intervention, in order to obtain information on where pupils bring their beverages from that they consume at school. The questionnaires were distributed in 14 out of 17 classes 1 and 2 (age 12-14 years) of intervention schools I and II, and 366 children completed the questionnaire (response rate $81 \%$ ). Almost half of them had the highest educational school level. The questionnaire contained 45 questions about drinking habits at school, categorized according to 'The Beverage Guidance Panel' [19]. Pre-categorized questions were asked about the number of days a week pupils drink beverages and water at school, the type (can, bottle, pack) and amount of items of beverages they drink per day at school, with categories, none, less than $1,1,2,3,4,5$, or more than 5 a day, and where the beverages were obtained (six categories; more options possible). Subsequently, the data were recalculated to the unit ' $\mathrm{ml} / \mathrm{pupil} /$ day.' For this recalculation, we made assumptions for the following categories: 'less than one item a day' and 'less than one time a week' were altered in respectively ' 0.5 items' and ' 0.5 times' and 'more than 5 items per day' was changed in ' 6 items'. The primary aim of the questionnaire was to investigate drinking habits of Dutch adolescents in order to contextualize the findings of the experiment. It was on purpose that the questionnaires were not distributed before or during the intervention period, in order to prevent questionnaire-induced behavioural change.

\section{Statistical Analysis}

Descriptive analyses were performed. Sales in sugar-sweetened beverages and changes during the intervention period were compared between intervention and control schools. We did not test potential differences in changing beverage sales between intervention and control schools, for three reasons: i) Data on whole beverage sales represent the total sales at schools. From that perspective, we did not do sampling. ii) If we would regard our few schools as a sample for 'all Dutch schools', numbers would become very small (schools are than the unit), and confidence intervals would be potentially large. iii) We did not have the intention to reduce 'chance'. It is our intention in this pilot study to provide a first impression on possible effectiveness.

\section{Results}

Table 1 shows the characteristics for the six participating schools, with a total of 5,866 pupils. Beverages could be purchased during the morning and afternoon breaks in the canteens if present and at all times from the vending machines. Schools had 1-3 vending machines in their school canteens. All, except one school, sold water, non-caloric and caloric beverages, beverages with some nutrients (sport drinks, fruit juices, and caloric sweetened beverages). One control school did not sell water and beverages with some nutrients. In one intervention and one control school, beverage sales were not restricted to vending machines.

Table 2 shows that sugar-sweetened beverages were the most frequently sold beverages in all school canteens during 
Table 3. Sugar-sweetened beverage sales in intervention and control schools before and during the intervention period (ml/pupil/day)

\begin{tabular}{lrrrrrr}
\hline & Pre-intervention* & \multicolumn{7}{l}{ Intervention period, weeks } \\
\cline { 4 - 7 } & & $1-3$ & $4-6$ & Christmas & $9-12$ & $13-16$ \\
\hline Intervention schools & & & & & & \\
$\quad$ I & 12.7 & 8.1 & 10.6 & 13.5 & 8.3 \\
II & 9.4 & 6.7 & 8.2 & 13.0 & 10.7 \\
III & 31.6 & 30.6 & 30.1 & 30.5 & 23.4 \\
Control schools & & & & & \\
$\quad$ IV & 8.1 & 5.7 & 5.4 & 5.4 & 8.6 \\
V & 18.9 & 14.5 & 17.3 & 13.3 & - \\
$\quad$ VI & 49.2 & 59.6 & 46.8 & 65.4 & 26.7 \\
\hline
\end{tabular}

*Pre-intervention period was a 6 weeks period from October to mid-November 2006. Intervention period lasted from mid-November 2006 until the end of February 2007, with 2 weeks Christmas break in between. the pre-intervention period. Sales of other beverages than sugar-sweetened beverages were small (less than $5 \mathrm{ml} /$ pupil/ day). Sweetened beverage sales were highest in schools in which beverage sales were not restricted to vending machines. On average, 35 pupils per day used the vending machines (approximately $5 \%$ of the total school population), and the amount of sweetened beverage sold at baseline was 17.9 and $25.5 \mathrm{ml} /$ pupil/day in intervention and control schools, respectively. No queues in front of vending machines were observed. The vending machines were mostly used by boys $(80 \%$ of purchases).

\section{Feasibility}

From the observations, it became clear that about $19 \%$ of water taps were performed during lunch breaks, $26 \%$ during morning/afternoon breaks, and $55 \%$ in-between breaks or before/after school hours. There were no queues in front of water coolers at any time. Water coolers were used slightly more by boys $(55 \%)$ than by girls $(45 \%)$. After 1 week, pupils did not use the water bottles anymore which were provided freely as part of the intervention. Instead, most of them used plastic water bottles. Some pupils drank water directly from the water tap and washed their hands with it. As leakage depots were rather small, dripping of water took place, and this was solved by canteen personnel without major problems. One incident occurred in which pupils removed the water discharge hose in order to be replaced by a condom. Water coolers have not been shut during the 3-month intervention period. Throwing with water was not observed and not reported by the school canteen personnel.

An average of 129 pupils/day (approximately 20\% of the school population) used the water coolers at the start of the intervention period, and the average volume per tap was approximately $400 \mathrm{ml}$. The mean volume of water consumption per pupil per day was highest at the start of the intervention period (67ml/pupil/day) and decreased steadily to $37 \mathrm{ml} /$ pupil/ day at the end of the intervention period (data not shown).

\section{Effects on Beverage Sales}

Table 3 shows that sales of sugar-sweetened beverages decreased, after the start of the intervention, but decreases were similar to decreases in control schools. Sales of sweetened beverages increased again after the first 3 weeks of the intervention period, and again, these changes were similar in intervention and control schools.

\section{Post-Intervention Questionnaire Data}

Based on the questionnaire that was taken after the intervention period, $37 \%$ of boys and $27 \%$ of girls consumed sugarsweetened beverages at school every day, and 24 and $44 \%$, respectively, reported no consumption of sugar-sweetened beverages at school at all. Mean consumption of sugar-sweetened beverages at school was 582 and $275 \mathrm{ml} /$ pupil/day among boys and girls, respectively. A total of $72 \%$ of sugar-sweetened beverages consumed at school is brought from home, and $24 \%$ of boys and $13 \%$ of girls reported to use the vending machines. A total of $32 \%$ of boys and $64 \%$ of girls reported to drink water at school on a daily basis, with an average water consumption at school of $457 \mathrm{ml} /$ day in boys and $745 \mathrm{ml} /$ day in girls. Water consumed at school is mainly taken from home (35\% among boys and 57\% among girls) and tapped from the tap in the toilet (52\% among boys and $48 \%$ among girls). A total of $78 \%$ of boys and $90 \%$ of girls reported that they expected to increase their water consumption with warm outside temperatures. When asked to recall the perceived impact of the free water coolers, $72 \%$ of boys and $69 \%$ of girls reported no perceived impact on the volume of beverages they drank (table 4).

\section{Discussion}

Placement of water coolers appeared to be a feasible intervention at secondary schools. Placement of water coolers, however, did not affect the sales of sugar-sweetened bever- 
Table 4. Beverage consumption at school ${ }^{\mathrm{a}}$ and sources of these beverages, among grade 1 and grade 2 pupils and sources of beverages, based on questionnaires that were filled out 3 months after the intervention (May 2007)

\begin{tabular}{|c|c|c|c|c|c|c|}
\hline & Water & $\begin{array}{l}\text { Non-caloric } \\
\text { beverages }\end{array}$ & $\begin{array}{l}\text { Non-sweetened milk } \\
\text { and dairy drinks }\end{array}$ & $\begin{array}{l}\text { Sweetened milk } \\
\text { and dairy drinks }\end{array}$ & Fruit juices & $\begin{array}{l}\text { Sugar-sweetened } \\
\text { beverages }\end{array}$ \\
\hline \multicolumn{7}{|l|}{ Boys $(n=171)$} \\
\hline \multicolumn{7}{|l|}{ Prevalence of use, $\%$} \\
\hline None & 16 & 70 & 92 & 76 & 55 & 24 \\
\hline$<1$ day a week & 14 & 16 & 1 & 7 & 8 & 15 \\
\hline 1-4 days a week & 39 & 11 & 5 & 10 & 20 & 24 \\
\hline Every day & 32 & 4 & 2 & 7 & 17 & 37 \\
\hline \multicolumn{7}{|l|}{ Drinks per pupil per day } \\
\hline Items/pupil/day (mean) & 1.3 & 0.6 & 0.3 & 0.4 & 0.9 & 1.8 \\
\hline ml/pupil/day (mean) & 457 & 173 & 74 & 107 & 252 & 582 \\
\hline \multicolumn{7}{|l|}{ Availability of drinks, $\%$ b } \\
\hline From home & 35 & 43 & 41 & 65 & 84 & 65 \\
\hline \multicolumn{7}{|l|}{ From school } \\
\hline - Vending machine & 1 & 34 & 6 & 0 & 3 & 24 \\
\hline - Tap from water cooler & 12 & - & - & - & - & - \\
\hline - Tap from the toilet & 52 & - & - & - & - & - \\
\hline From supermarket & 2 & 17 & 0 & 2 & 5 & 16 \\
\hline \multicolumn{7}{|l|}{ Girls $(n=195)$} \\
\hline \multicolumn{7}{|l|}{ Prevalence of use, $\%$} \\
\hline None & 7 & 75 & 92 & 84 & 54 & 44 \\
\hline$<1$ day a week & 6 & 10 & 3 & 3 & 9 & 8 \\
\hline 1-4 days a week & 24 & 10 & 2 & 9 & 24 & 21 \\
\hline Every day & 64 & 5 & 4 & 4 & 14 & 27 \\
\hline \multicolumn{7}{|l|}{ Drinks per pupil per day } \\
\hline Items/pupil/day (mean) & 1.9 & 0.2 & 0.2 & 0.1 & 0.5 & 0.8 \\
\hline ml/pupil/day (mean) & 745 & 59 & 42 & 28 & 147 & 275 \\
\hline \multicolumn{7}{|l|}{ Availability of drinks, $\%^{b}$} \\
\hline From home & 57 & 59 & 71 & 58 & 89 & 81 \\
\hline \multicolumn{7}{|l|}{ From school } \\
\hline - Vending machine & 0 & 25 & 0 & 6 & 7 & 13 \\
\hline - Tap from water cooler & 10 & - & - & - & - & - \\
\hline - Tap from the toilet & 48 & - & - & - & - & - \\
\hline From supermarket & 1 & 4 & 6 & 6 & 2 & 13 \\
\hline
\end{tabular}

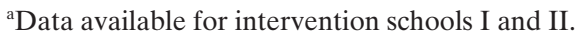

${ }^{\mathrm{b}}$ Amongst users.

ages at schools. Although mean intake of sugar-sweetened beverages at school was high (more than $500 \mathrm{ml} /$ day for boys and more than $250 \mathrm{ml} /$ day for girls), only a minor part of these drinks were purchased at school.

To our knowledge, this is the first study examining the impact of a single-issue intervention providing free water on beverage sales at secondary schools. Our results were in line with conclusions by Loughridge and Barratt [29] who studied the impact of paid water provision at schools on cognitive determinants during 3 months. Loughridge and Barrat [29] had three intervention arms for their study. The first school received, besides the water coolers, promotion about the health benefits of drinking water by posters and verbal informing. The second school received water coolers without promotion, and the third school was the control school. The consumption of water was significantly higher in the school who also received promotion materials, but the purchased volume of sugar-sweetened beverages remained fairly static in all three schools. When combined with an educational intervention, an elegant trial by Muckelbauer et al. [31] showed that provision of drinking water could be effective in the prevention of overweight among children in elementary school.

An important step in intervention research is feasibility [11]. Feasibility of obesity prevention programmes is particularly hard since many determinants, many stakeholders, and many settings are involved in the development of obesity [1014]. Feasibility of interventions targeting a single behaviour, a single determinant of behaviour, and a single setting seems to be large, as confirmed from the present study, but the evidence of the effectiveness of these 'relatively simple' interventions is poorly documented. 
Canteen keepers mentioned that pupils were enthusiastic about the free water coolers and that the water tasted better than the water tapped from the taps in the toilets. Pupils did not misuse the water coolers and the coolers stayed operable continuously. Water consumption decreased during the intervention, but this is most likely explained by changing seasons. Most boys and girls reported that they expected to increase their water consumption with warm outside temperatures.

Advantages of our study are the relatively high participation rates of schools, the objective, repeated recording of beverage sales, the addition of a process evaluation, and the use of questionnaire data on 'total' sweetened beverage consumption at school. Limitations are the small size of this pilot study and the absence of a randomization procedure. We did not test differences in changes in beverage sales between intervention and control schools statistically. Please note that testing would not have made sense since we conclude that changes in beverage sales did not differ between intervention and control schools. Hence, the absence of evidence does not imply an evidence for absence. We do not know whether beverage consumption from other sources like home and local supermarket has changed, and we did not include consumption of beverages outside school. Moreover, we do not know to what extent water consumed from other sources, like toilets, home or local supermarket, has changed. Before concluding whether placing water coolers affects 'total' sugarsweetened beverage consumption at school and outside school, evaluation should compare data on different sources within and outside schools, before, during and after the intervention period.

Timing of the current pilot study was not fortunate as soft drink sales are higher in summer than in winter time. However, although the effect of water coolers on soft drink sales may be higher in the summer due to higher baseline sales, we believe that that the current conclusion that soft drink consumption from vending machines only explains a minority of the total soft drink consumption at school remains valid in summer. Thus, even in summer, reducing soft drink sales in school canteens should not be prioritized.

This pilot study has been performed on request by the Dutch Ministry of Health, Welfare and Sport in order to serve as preparation for a larger trial aiming at studying the impact of free water provision on total beverage consumption, including other sources of water and sweetened beverage consumption than studied here. The health benefit of drinking water has been questioned in exhaustive reviews as strong evidence is surprisingly scarce [32]. However, the benefits of drinking water from this pilot's perspective should not be seen as benefit from dinking water per se, but from a perspective of drinking none or less sugar-sweetened beverages. On basis of the current finding that beverage sales in schools were only small, we will need to reconsider the need for prioritizing provision of free water at secondary school canteens to alternative health promotion interventions. Schools should not be discouraged, however, if they are aiming at placing water coolers already. Hence, no disadvantages were recorded, and even in the absence of effectiveness, placing water coolers can be viewed as an improvement in the 'obesogenic school environment,' making the healthy choice easier.

\section{Conclusions}

Placing water coolers as a single-issue intervention turned out be a feasible intervention at secondary schools. However, from the current pilot study we carefully conclude that placing water coolers was not effective on reducing the sales of sugarsweetened beverages at schools, and sales of sugar-sweetened beverages in secondary school canteens, at least in the Netherlands, are only small. Thus, placing water coolers as a single-issue intervention in secondary school canteens should not be prioritized in the combat against obesity.

\section{Authors' Contributions}

TLSV and WJEB participated in the conception and design of the study, interpretation of the data and have been involved in revising the manuscript critically for important intellectual content. TLSV drafted the final manuscript. WCWH performed the analysis and interpretation of the data. LB has made contributions to the design of the study and acquisition of data. CMR and JCS have been involved in revising the manuscript critically for important intellectual content. All authors read and approved the final manuscript.

\section{Acknowledgements}

This study was supported by The Ministry of Health, Welfare and Sport. We are grateful to Ms. Naomi Reitsma for her contribution to the development of the study and collecting of the data, and to Mrs. Saskia van Helden for communication with the water distribution company. Cooperation of Mr. Marcel Lips from Vitens and their free provision of water coolers and water bottles is gratefully acknowledged.

\section{Disclosure}

The author(s) declare that they have no competing interests. The water distribution company Vitens had provided the water coolers and water bottles for free but had no influence on the design of the study nor on the analyses and interpretation of the results. 


\section{References}

1 Lobstein T, Baur L, Uauy R: Obesity in children and young people: a crisis in public health. Obe Rev 2004;5(suppl 1):4-104.

2 Van den Hurk K, van Dommelen P, de Wilde J, Verkerk P, van Buuren S, Hirasing RA: Prevalence of overweight and obesity in the Netherlands in 2003 compared to 1980 and 1997. Arch Dis Child 2007;92:992-995.

3 Schokker DF, Visscher TLS, Nooyens ACJ, van Baak MA, Seidell JC: Prevalence of overweight and obesity in the Netherlands. Obes Rev 2007;8:101-108.

4 Dietz W: Health Consequences of obesity in youth childhood predictors of adult disease. Pediatrics 1998:101:518-525.

5 Singh AS, Chin A Paw MJ, Kremers SPJ, Visscher TLS, Brug J, van Mechelen W: Design of the Dutch Obesity Intervention in Teenagers (NRGDOiT): systematic development, implementation and evaluation of a school-based intervention aimed at the prevention of excessive weight gain in adolescents. BMC Public Health 2006;6:304.

6 Story M, Kaphingst KM, French S: The role of schools in obesity prevention. Future Child 2006; 16:109-142.

7 Doak CM, Visscher TLS, Renders CM, Seidell JC: The prevention of overweight and obesity in children and adolescents: a review of interventions and programmes. Obes Rev 2006; 7:111-136.

8 Summerbell CD, Waters E, Edmunds LD, Kelly S, Brown T, Campbell KJ: Interventions for preventing obesity in children. Cochrane Database Syst Rev 2005:CD001871.

-9 Brown T, Summerbell C: Systematic review of school-based interventions that focus on changing dietary intake and physical activity levels to prevent childhood obesity: an update to the obesity guidance produced by the National Institute for Health and Clinical Excellence. Obes Rev 2009;10: 110-141.
10 Kremers SPJ, de Bruijn GJ, Visscher TLS, van Mechelen W, de Vries NK, Brug J: Environmental influences on energy balance-related behaviors: a dual-process view. Int J Behav Nutr Phys Act 2006;3:9.

11 Swinburn B, Gill T, Kumanyika S: Obesity prevention: a proposed framework for translating evidence into action. Obes Rev 2005;6:23-33.

12 Swinburn B, Egger G, Raza F: Dissecting obesogenic environments: the development and application of a framework for identifying and prioritizing environmental interventions for obesity. Prev Med 1999;29:563-570.

13 Egger G, Swinburn B: An 'ecological' approach to the obesity pandemic. BMJ 1997;315:477-480.

14 WHO: The Challenge of Obesity in the WHO European Region and the Strategies for Response. Copenhagen, World Health Organisation, 2007.

15 Bell AC, Swinburn BA: What are the key food groups to target for preventing obesity and improving nutrition in schools? Eur J Clin Nutr 2004;58: 258-263.

16 Libuda L, Kersting M: Soft drinks and body weight development in childhood: is there a relationship? Curr Opin Clin Nutr Metab Care 2009;12:596-600.

17 French SA, Lin BH, Guthrie JF: National trends in soft drink consumption among children and adolescents age 6 to 17 years: prevalence, amounts, and sources, 1977/1978 to 1994/1998. J Am Diet Assoc 2003;103:1326-1331.

18 Nielsen SJ, Popkin BM: Changes in beverage intake between 1977 and 2001. Am J Prev Med 2004;27: 205-210.

19 Popkin BM, Armstrong LE, Bray GM, Caballero B, Frei B, Willett WC: A new proposed guidance system for beverage consumption in the United States. Am J Clin Nutr 2006;83:529-542.

20 Gezondheidsraad: Enkele ontwikkelingen in de voedselconsumptie. Den Haag, Gezondheidsraad, 2002.

21 Berkey CS, Rockett HR, Field AE, Gillman MW, Colditz GA: Sugar-added beverages and adolescent weight change. Obes Res 2004;12:778-788.
22 Ebbeling CB, Feldman HA, Osganian SK, Chomitz VR, Ellenbogen SJ, Ludwig DS: Effects of decreasing sugar-sweetened beverage consumption on body weight in adolescents: a randomized, controlled pilot study. Pediatrics 2006;117:673-680.

23 Ludwig DS, Peterson KE, Gortmaker SL: Relation between consumption of sugar-sweetened drinks and childhood obesity: a prospective, observational analysis. Lancet 2001;357:505-508.

24 Anderson P, Butcher K, Levine P: Economic perspectives on childhood obesity. Economic Perspectives 2003; Q3:30-48.

25. Anderson PM, Butcher KE: Childhood obesity: trends and potential causes. Future Child 2006;16: 19-45.

26 Fox S, Meinen A, Pesik M, Landis M, Remington PL: Competitive food initiatives in schools and overweight in children: a review of the evidence. Wis Med J 2005;104:38-43.

27 Neumark-Sztainer D, French SA, Hannan PJ, Story M, Fulkerson JA: School lunch and snacking patterns among high school students: associations with school food environment and policies. Int $\mathrm{J}$ Behav Nutr Phys Act 2005;2:14.

28 Swinburn BA, Jolley D, Kremer PJ, Salbe AD, Ravussin E: Estimating the effects of energy imbalance on changes in body weight in children. Am J Clin Nutr 2006;83:859-863.

29 Loughridge JL, Barrat J: Does the provision of cooled filtered water in secondary school cafeterias increase water drinking and decrease the purchase of soft drinks? J Hum Nutr Diet 2005;18:281-286.

30 Convenant overgewicht: Een balans tussen eten en bewegen. Den Haag, Convenant Overgewicht, 2005.

31 Muckelbauer R, Libuda L, Clausen K, Toschke AM, Reinehr T, Kersting M: Promotion and provision of drinking water $\mathrm{n}$ schools for overweight prevention: randomized, controlled cluster trial. Pediatrics 2009;123:e661-e667.

32 Negoianu D, Goldfarb S: Just add water. J Am Soc Nephrol 2008;19:1041-1043. 